\title{
ФЕНОМЕН ЦИФРОВОЙ ТРАНСФОРМАЦИИ ЭКОНОМИКИ В РАЗВИТИИ ОБЩЕСТВА
}

\begin{abstract}
В.Л. Гурский*
Исследуются феноменологические основы цифровой трансформации экономики в контексте изменения социально-экономических отношений, обусловленных эволюцией средств производства в результате НТП. Анализируются основные преимущества и угрозы, связанные с цифровой трансформацией общества. В качестве обязательного условия сокращения ее рисков рассматривается государственный контроль за информационными ресурсами, коммуникационными платформами, техническими и программными средствами передачи, обработки и хранения данных.
\end{abstract}

Ключевые слова: цифровая экономика, цифровая трансформация, киберфизические комплексы, виртуальная реальность.

JEL-классификация: O33.

DOI: $10.46782 / 1818-4510-2021-3-4-14$

Материал поступил 30.07.2021 2.

В 2009 г. в США начали реализовывать так называемую облачную стратегию с целью создания «умных» производств, городов, транспортных систем и решения задач социального характера. В 2010 г. разработана программа «Цифровая Европа» для развития интернет-экономики в ЕC. Кроме того, отдельно в Германии в 2011 г. принята стратегия «Индустрия 4.0», направленная на развитие промышленного Интернета и интернета вещей. В КНР в 2015 г. разработана стратегия «Интернет+» ${ }^{1}$. В 2019 г. утверждена Национальная программа «Цифровая экономика Российской Федерации», в феврале 2021 г. - Государственная программа «Цифровое развитие Беларуси на 2021-2025 годы». Основная цель

${ }^{1}$ Анализ мирового опыта развития промышленности и подходов к цифровой трансформации промышленности государств - членов Евразийского экономического союза: информационно-аналитический отчет. 2017. C. 13. URL: http:// www.eurasiancommission.org/ru/act/ prom_i_agroprom/dep_ prom/SiteAssets/Pages /Мониторинг\%20и\%20анализ sectorreview / ЦИФРОВАЯ\%20ТРАНСФОРМАЦИЯ\% 20ПРОМЫШЛЕННОСТИ\%2013.02.2017.pdf обозначенного процесса, получившего название «цифровая трансформация экономики», - внедрение информационно-коммуникационных и передовых производственных технологий в отрасли национальной экономики и сферы жизнедеятельности общества ${ }^{2}$.

Можно с уверенностью утверждать, что цифровая трансформация экономики и общества является одним из основных трендов социально-экономического развития общества на современном этапе, который обуславливает переход к новому технологическому укладу. Сегодня уже совершенно очевидно: цифровая трансформация экономики - неизбежный процесс, связанный с появлением новых средств производства и социального взаимодействия в результате НТП.

В экономической литературе процессы цифровой трансформации нашли достаточно широкое освещение. Они рассматриваютC22100066

${ }^{2}$ URL: https://pravo.by/document/?guid $=3871 \&$ p0 $=$

* Гурский Василий Леонидович (vhurski@yandex.by), доктор экономических наук, доцент, Институт экономики НАН Беларуси (г. Минск, Беларусь). https://orcid.org/0000-0001-5474-9111 
ся в работах отечественных авторов, таких как: В.Ф. Байнев (Байнев, Бинь, 2017), Н.И. Богдан (2018), М.М. Ковалев, Г.Г. Головенчик (2018), П.С. Лемещенко (2019), Б.Н. Паньшин (2016), С.Ю. Солодовников (2019), Ю.В. Мелешко (2018) и др. Вопросы цифровизации экономики раскрыты в работах российских исследователей С.Ю. Глазьева (2017), Т.Н. Юдиной (2016), А.С. Никитина, И.И. Борисенко (2020), А.Н. Козырева (2018) и др. Среди зарубежных ученых можно выделить М. Кастельса (2000), Т. Мезенбурга (2001), К. Шваба (2016), Б. Карлссона, Б. Йоханссона, Р. Стоу (2006) и др.

Вместе с тем единого понимания сущности цифровой трансформации в экономической науке пока не сформировалось. В литературе встречается много определений понятия «цифровая экономика». А.А. Энговатова (МГУ им. М.В. Ломоносова) дает следующую формулировку: «Цифровая экономика - это экономика, которая основана на новых методах генерирования, обработки, хранения, передачи данных, а также цифровых компьютерных технологиях» (Филиппова, Незванов, 2018). Определение В.В. Иванова (член-корреспондент РАН): «Цифровая экономика - виртуальная среда, которая дополняет нашу реальность. При этом виртуальная реальность - это все же продукт мыслительной деятельности человека, а появление компьютера позволило ее оцифровать» ${ }^{3}$.

Цель статьи - исследовать феноменологическую сущность процесса цифровой трансформации экономики в контексте новых вызовов и возможностей для общества, связанных с ней.

\section{Цифровая трансформация сочиально- әкономических отношений}

Обобщая существующие формулировки и учитывая признаки цифровой экономики, можно определить феномен цифровой трансформации как изменение системы социально-экономических отношений на основе широкого внедрения цифровых средств производства, которое выражается в формировании новых рынков и отрас-

${ }^{3}$ Цифровая экономика: как специалисты понимают этот термин. РИА Новости. URL: https://ria.ru/20170616/ 1496663946.html лей, новых моделей управления и новых моделей поведения потребителей.

Как уже отмечалось нами ранее, концепция цифровой трансформации экономики - «..это не просто комплекс идей по автоматизации производства на основе цифровых технологий. Искусственный интеллект, трехмерная печать, интернет вещей, промышленный интернет, «умные» дома и «умные» заводы, роевые технологии, виртуальная и дополненная реальность - это лишь внешние атрибуты четвертой промышленной революции, которая называется революцией именно потому, что изменения происходят не поверхностные, а радикальные» (Гурский, 2017).

Технологии «больших данных» позволяют осуществлять глобальную координацию деятельности киберфизических систем в реальном времени как между собой, так и с социальными системами (начиная от бытовой техники и заканчивая государством). При этом цифровое общение начинает преобладать над живым общением, а виртуальная реальность часто становится более значимой, чем физическая.

Образование информационного общества сопровождается информационным взрывом. Появление и развитие цифрового общества дополнительно включает две важнейшие составляющие:

1) формирование и развитие интернета вещей, представляющего собой новую форму взаимодействия киберфизических систем, которые коммуницируют между собой посредством Интернета без непосредственного участия человека. В настоящее время к Интернету в мире уже подключено более 22 млрд устройств;

2) формирование и развитие интернета людей - новой социальной среды, которая образуется в виртуальном пространстве и предоставляет пользователям новые возможности для коммуникации, где о человеке (почти вне его собственного желания) можно получить информации больше, чем он знает сам о себе. Этот процесс включает создание интернет-магазинов и служб доставки, оцифровку библиотечных и архивных фондов, проведение научных и культурных мероприятий онлайн, появление виртуальных двойников реальных объектов 
культуры и архитектуры для проведения виртуальных туров, формирование электронного государства, коммунальных служб и др.

Согласно данным мировых рейтинговых агентств, в 2020 г. в мире насчитывалось порядка 5,2 млрд уникальных мобильных пользователей (это 67\% всего населения Земли) (рис. 1), мировая аудитория Интернета составляла 4,5 млрд чел. (59\%) (рис. 2), в социальных сетях зарегистрировано 3,8 млрд пользователей (49\%) (рис. 3).

Цифровая составляющая открывает новые возможности для индивида, связанные прежде всего с доступностью информации. Ограниченная информированность всегда была фактором, ограничивающим рациональность принятия экономических решений индивида или иного субъекта хозяйствования.

Как отмечает Ю.В. Мелешко (2018), «...наиболее перспективным представляется использование данной технологии (интернета вещей. - B.Г.) в производственном сегменте. Правительствами разных стран разрабатываются программы, нацеленные на цифровизацию промышленности: в США - «Промышленный ренессанс», в Китае - «Производство 2025» или «Интернет плюс», в Германии - «Промышленность $4.0 »$ или «Промышленная революция 4.0», во Франции - «Креативная индустрия» или «Индустрия будущего». Новые технологии не просто расширяют возможности производителей по производству и продвижению товаров, но позволяют создавать товары с принципиально новыми характеристиками. «Развитие технологий в производстве товаров интенсивного обновления привело к возникновению так называемого электронного текстиля (от англ. «electronic textiles») и созданию умной одежды (от англ. «smart garments», «smart clothing»)», - пишет Т.В. Сергиевич (2019) и далее отмечает: «Специальные датчики способны отслеживать состояние здоровья человека на основе аккумулирования информации о сердечном ритме, давлении, температуре тела; солнечные батареи позволяют заряжать электронные девайсы; нагревающие элементы дают возможность одежде регулировать температуру; светодиоды реагируют на изме-

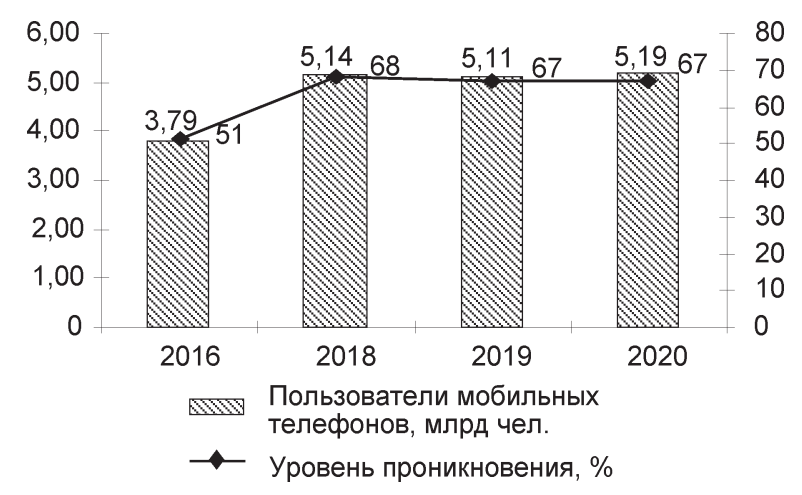

Рис. 1. Количество пользователей мобильными телефонами в мире в динамике

Источник. Авторская разработка по отчетам о состоянии цифровой сферы Global Digital за период 2016-2020 гг.

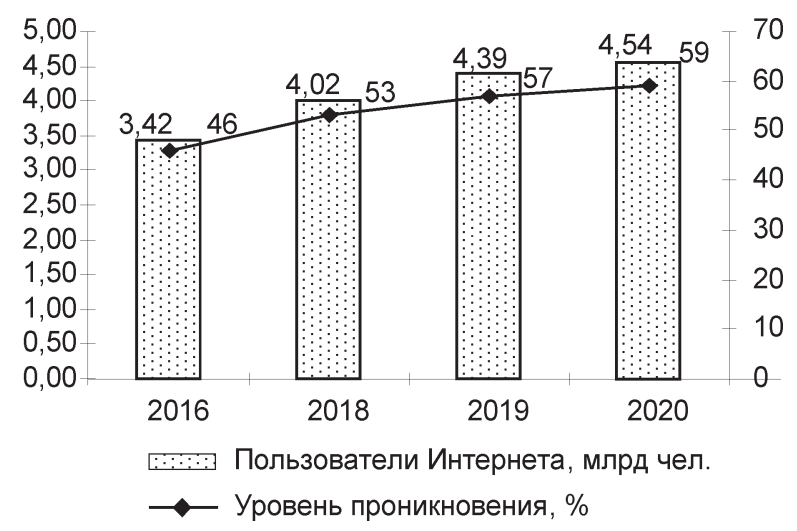

Рис. 2. Количество пользователей Интернета в мире в динамике

Источник. Авторская разработка по отчетам о состоянии цифровой сферы Global Digital за период 2016-2020 гг.

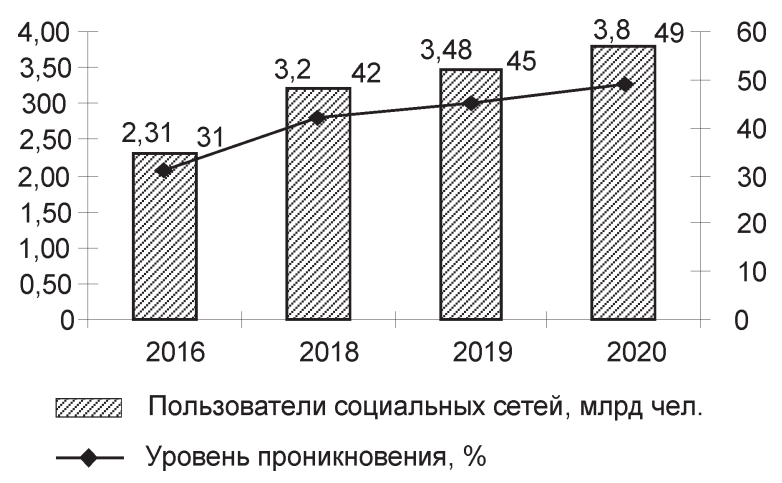

Рис. 3. Количество пользователей социальных сетей в мире в динамике

Источник. Авторская разработка по отчетам о состоянии цифровой сферы Global Digital за период 2016-2020 гг. 
нение настроения, получая информацию о мозговой активности человека». Новые возможности в производстве и в коммуникациях создают предпосылки для изменений в структуре отношений между производителями и потребителями. Вместо массового производства происходит переориентация на кастомизацию, ориентированную на индивидуального покупателя и единичное производство. При этом затраты на производство и реализацию кастомизированного товара, произведенного в единичном экземпляре, вполне сопоставимы с затратами на аналогичный товар при массовом производстве, что приводит к усилению конкурентной борьбы между крупными и мелкими производителями. Снижение затрат происходит не только за счет технологий и технических средств, но и за счет новых форм организации экономического процесса. Как пишет Т. Гудвин: «рупнейшая в мире компания такси Uber не является собственником транспортных средств. Самый популярный в мире медийный собственник Facebook не создает контента. Самый дорогостоящий розничный продавец Alibaba не имеет товарного запаса. Крупнейший в мире поставщик услуг по временному проживанию Airbnb не является владельцем недвижимости» ${ }^{4}$. Поэтому владение платформой становится более важным, чем владение базовым активом.

Вместе с тем основные направления распространения инноваций цифровой трансформации промышленности связаны именно с международными цепочками добавленной стоимости (вне зависимости от того, насколько велика или мала доля того или иного звена). Данная особенность обусловлена спецификой цифровизации технологического процесса в рамках концепции «умных» производств (Smart Manufacturing), цифровой логистики и технологий промышленной «аналитики 3.0». Внедрение всех вышеперечисленных технологий требует совместимости технологических цифровых платформ для всех участников одной цепочки создания продукта, т. е. внедрение «умного» производства на головном предприятии в стране, являющей-

${ }^{4}$ URL: http://techcrunch.com/2015/03/03/in-the-ageof-disintermediation-the-battle-is-all-for-thecustomer-interface/ ся технологическим лидером, не может произойти изолированно от поставщиков и смежников, где бы они ни находились. Сквозная автоматизация и интеграция производственных и управленческих процессов в единую информационную систему, применение сервисов по автоматическому заказу расходных материалов, сырья и комплектующих, переход на обязательную оцифрованную техническую документацию и электронный документооборот, массовое внедрение интеллектуальных датчиков в оборудование, производственные линии, запчасти и комплектующие на любом из предприятий технологической цепочки не могут произойти без соответствующих нововведений у партнеров. Деталь, не имеющая цифрового макета на совместимой платформе, разработанная отдельно от общего цифрового образа производимого изделия, не оснащенная соответствующими цифровыми интерактивными маркерами или датчиками, останется невостребованной в цифровом производстве следующего звена цепочки добавленной стоимости.

Инновационная конкуренция крупнейших международных корпораций представляет собой соперничество новых технологий в формировании рыночных стандартов, и прежде всего используемых цифровых платформ. Расширение рынка сбыта напрямую зависит от прихода новых партнеров, обладающих соответствующими технологиями и способных интегрировать продукт в свою программную среду. Привлечение партнеров осуществляется в том числе посредством предоставления им доступа к инновационной технологии (например, конкуренция операционных систем для мобильных устройств Android (Google) и Symbian (Nokia, Sony Ericsson, Motorola), что открывает новые «окна» возможностей как для отдельных субъектов хозяйствования, так и для промышленной политики государства в целом.

В докладе Национального разведывательного совета США «Глобальные тенденции 2030: альтернативные миры» отмечается, что через 15-20 лет крупнейшие государства утратят способность проецировать свое влияние в глобальном масштабе, что приведет к распределению (или рассре- 
доточению) контроля над положением дел в мире между государственными механизмами, социальными сетями и негосударственными структурами. С развитием коммуникационных технологий основными центрами силы станут многофункциональные сети, состоящие из государственных и негосударственных субъектов, образованные в целях оказания влияния на глобальную политику в различных сферах. Такие сети за счет включения в них разнообразных и многочисленных игроков будут в значительной степени определять и сдерживать действия традиционных государственных субъектов ${ }^{5}$.

Более широкие возможности для коммуникаций между субъектами позволяют существенно снизить трансакционные издержки и ограничивают возможности для оппортунистического поведения. Вместе с тем этот процесс двусторонний. Получая доступ к информации о других участниках экономических отношений, каждый субъект сам становится более открыт. В цифровой экономике это происходит даже без согласия участника. Технологии больших данных позволяют в автоматическом режиме отслеживать информационные запросы, закупки, продажи, перемещения субъекта в реальном времени и формировать его цифровой портрет, который может содержать больше информации, чем ему бы хотелось. Новая реальность меняет структуру отношений в обществе, мотивацию и запросы человека.

\section{Плюсъ и минусъ ицфровой трансформации}

Как и любые изменения в структуре общественных отношений, цифровая трансформация предполагает и новые возможности, и новые вызовы.

Положительными сторонами цифровой трансформации являются:

- многократный рост производительности труда и удельной добавленной стоимости на одного работника за счет автоматизации и роботизации производственных процессов, значительного увеличения цифровой продукции с высокой добавлен-

5 URL: http://mgimo.ru/files2/y09_2013/241324/ zak692_ad3_38nikitin_obl2web.pdf ной стоимостью в структуре производства и потребления;

- снижение затрат на единицу продукции за счет снижения трансакционных и транспортно-логистических издержек, сокращения ручного труда, брака, более рационального использования ресурсов;

- появление новых товаров и услуг, прежде всего информационно-коммуникационного характера, что может стать мощным драйвером экономического роста компаний и стран;

- возможность самостоятельного создания дистанционных рабочих мест и новых форм бизнеса, предполагающих прямое взаимодействие потребителя и поставщика через Интернет;

- существенное повышение качества услуг, в том числе государственных и жилищно-коммунальных за счет возможности почти мгновенно решать возникающие вопросы в удаленном режиме путем внедрения новых решений, таких как цифровое государство, «умные» города и дома.

Вместе с тем выделяют определенные риски и угрозы цифровой трансформации:

- появление психических расстройств у людей по причине гиперподключенности и замены живого общения между людьми общением цифровым, в том числе с чат-ботами и искусственным интеллектом;

- угроза информационному суверенитету стран и конфиденциальности граждан, связанная с появлением возможности использовать платформы социальных сетей для сбора и анализа данных о поведении пользователей как в Интернете, так и в реальной жизни;

- рост киберопасности, включая различные виды киберпреступности и кибертерроризма;

- появление дисбаланса на рынках труда вследствие трансформации структуры экономики и новых требований к компетенциям работников;

- обострение проблем социально-экономического неравенства, роста децильных коэффициентов и «цифрового разрыва» между индивидами, организациями и странами;

- обострение правовых и этических проблем, связанных с самостоятельностью принятия решений машинами (беспилотный автотранспорт); 
- выход киберсистем из-под контроля человека, обусловленный чрезвычайной сложностью новой системы и невозможностью ее контролировать непосредственно человеком и необходимостью использования одних киберсистем для контроля других. Здесь речь идет не столько о восстании машин, для этого у них просто отсутствуют мотивы, а о возможности техногенных катастроф и др.

Цифровая трансформация касается практически всех сфер общественной жизни. Переход к модели цифровой экономики и цифрового общества в мировом масштабе сопровождается принципиально новыми, качественными изменениями социально-экономических отношений как на уровне государства и бизнес-структур, так и на уровне индивидов. В этой связи «...концепция государственной промышленной политики неизбежно будет трансформироваться как в области целевых установок, так и в области инструментарных средств и механизмов их применения. С одной стороны, технологии «больших данных» дадут возможность государственным структурам получать более полную информацию о процессах, протекающих в экономике, и быстрее на них реагировать, с другой - субъекты хозяйствования получат больше возможностей оказывать влияние на макроэкономическую политику государства» (Гурский, 2017). Поэтому цифровая экономика - это не столько компьютеры и программное обеспечение, сколько новая форма управления социально-экономическими процессами в обществе.

В Китае с 1 декабря 2019 г. стала обязательной процедура распознавания лица при использовании Интернета с целью защиты от киберпреступников и мошенников. А с 1.01.2021 г. в соответствии с новым гражданским кодексом началось внедрение «системы социального доверия». Суть концепции социального доверия (рейтинга) заключается в применении средств цифрового мониторинга для оценки деятельности граждан. Оценка каждого человека осуществляется в баллах, сумма которых меняется в зависимости от его поведения, и определяет возможность для него пользоваться социальными благами. Балль- ная система действует и в отношении юридических лиц.

Необходимо отметить, что подобные системы «рейтингов» уже давно существуют во всем мире в отдельных сферах общественной жизни, например в системе банковского кредитования (ваша кредитная история), обязательного страхования автогражданской ответственности, системе учета налогоплательщиков и др. В КНР рейтинговая система получила более комплексный характер.

С одной стороны, такой подход призван кардинально упорядочить жизнь общества, с другой - может стать фактором для масштабных искажений восприятия действительности сквозь призму искусственно установленной шкалы. Принципиально важно, какие именно аспекты жизни человека принимаются и какие критерии закладываются в систему оценки его поведения, как контролируется сбор и ввод данных в систему, насколько соблюдается равное выполнение единого для всех алгоритма.

Цифровая трансформация остро ставит вопрос - кому можно доверить фактический контроль технического и программного обеспечения цифровой стороны жизни общества и насколько этот процесс будет соответствовать интересам самого общества. Даже самые совершенные в плане безопасности системы и базы данных могут оказаться в руках преступников или заинтересованных лиц. В настоящее время контроль в основном находится в руках международных корпораций. Наиболее ярко эта проблема проявила себя в период последних выборов президента США, когда на определенном этапе аккаунт Дональда Трампа решением крупнейших IT-компаний был заблокирован группой социальных сетей. Фактически, действующий на тот момент президент США оказался отрезан от привычных ему средств коммуникации. Корпорации продемонстрировали, что готовы и могут диктовать свои правила.

В своей книге «Четвертая промышленная революция» К. Шваб (2016. С. 27) утверждал: «Прорыв в сфере существующих политических, экономических и социальных моделей в результате четвертой промышленной революции потребует от само- 
стоятельно действующих лиц признания себя частью системы распределенной власти, которая предусматривает коллективные формы взаимодействия». «Четвертая промышленная революция ... окажет влияние на смещение власти не только в географическом отношении, но и от государственных структур к негосударственным» (Там же. С. 65). Это произойдет прежде всего потому, что регулирующие органы будут отставать от стремительно нарастающих технологических достижений. Очевидно, что преимущества получат те субъекты управления, которые смогут контролировать технологии (и технические средства), обеспечивающие координацию деятельности киберфизических систем. Как уже отмечалось нами ранее, «...основная задача государства, если оно стремится сохранить свое влияние в вопросах определения приоритетов экономической (промышленной) и социальной политики, обеспечить ускоренный переход процессов координации экономического процесса в стране и механизмов реализации промышленной политики на цифровую основу» (Гурский, 2017). Чрезвычайно важно, чтобы используемые информационные ресурсы, коммуникационные платформы, технические и программные средства передачи, обработки и хранения данных находились под контролем социально ответственного государства, а не корпораций, нацеленных на получение прибыли и доминирование на рынке.

В гонку за лидерство в цифровой сфере включились практически все крупные государства. Китай в последние годы вкладывает огромные средства в развитие технологий искусственного интеллекта, телекоммуникационных сетей $5 \mathrm{G}$ и $6 \mathrm{G}$, догоняя, а в чем-то и опережая США. Американцы прилагают значительные усилия по сдерживанию развития КНР в «технологической гонке», в частности не допускают компанию Huawei к развертыванию сетей $5 \mathrm{G}$ в своей стране и странах западной Европы, запрещают американским компаниям поставлять программное обеспечение и компоненты китайским компаниям. Подобные инструменты «технологического сдерживания» используются и в отношении России и других стран.

\section{Цифровая трансформация в Беларуси}

В Беларуси значение внедрения и использования цифровых технологий осознается на высшем политическом уровне. «Цифровая трансформация экономики является одним из ключевых приоритетов развития государства», - не раз отмечал Президент Республики Беларусь А.Г. Лукашенко. Принятие сначала Декрета № 8 «О развитии цифровых технологий», а позже Государственной программы «Цифровое развитие Беларуси» на 2021-2025 годы дало старт масштабным изменениям. Следует отметить, что в нашей стране создана уникальная налоговая и правовая среда, благоприятная для развития цифровой экономики и ИТ-сектора. Искусственный интеллект и робототехника стали одним из приоритетных направлений научной, научно-технической и инновационной деятельности на 2021-2025 гг. В развитии и распространении инновационных технологий Беларусь опирается в основном на собственные научные исследования и разработки. Развитие собственной науки один из приоритетов белорусской инновационной политики. Белорусская экономическая модель имеет научную основу и все последнее время выстраивалась на основе теоретико-методологических наработок отечественных ученых.

Республика Беларусь в настоящее время довольно успешно осваивает новейшие уклады. Сюда можно отнести IT- и космические технологии, атомную энергетику, нано- и биотехнологии и многие другие. Предполагается, что в перспективе они должны доминировать. Цифровизация производственных процессов пока идет точечно. В первую очередь это касается этапов проектирования, в том числе с использованием технологий цифровых двойников (ОАО «МЗКТ» и др.), а также систем управления ресурсами (ERP-систем). Например, OAO «БЕЛАЗ» (управляющая компания холдинга «БЕЛАЗ-ХОЛДИНГ») реализовывался проект «Развитие действующей системы электронного управления ресурсами предприятия». РУП «Минскэнерго» продолжены развитие и поддержка автоматизации бизнес-процессов на основе платформы 
$1 \mathrm{C}-\ll 1 \mathrm{C}$ : Предприятие 8. Минскэнерго». РУП «Брестэнерго» введен в промышленную эксплуатацию модуль «Оперативный и бухгалтерский учет запасов и оборудования». В ОАО «Гомельдрев» и ПУП «Гомельобои» внедрен программный комплекс управления предприятием, построенный на платформе «Гедымин» компании Golden Software of Belarus, Ltd, г. Минск. В рамках промышленной политики Республики Беларусь запланированы меры по использованию в промышленности автономных производственных комплексов, систем управления на основе концепции «интернет вещей», технологий аддитивного производства. Цифровизация традиционных видов деятельности предусматривает внедрение в крупных и средних промышленных организациях автоматизированных систем управления товарными потоками, ERP-систем и CALS-технологий; создание систем диспетчерского управления сбора данных (SCADA), SMC-систем (управление цепочками поставок). Намечены меры по установке на предприятиях систем передачи и обработки данных в формате 5G с целью управления роботизированными производственными процессами и использования 3D-печати.

Проектом Национальной стратегии устойчивого развития Республики Беларусь до 2035 года предусматривается, что процесс цифровизации промышленного комплекса будет выстраиваться путем внедрения систем управления на основе концепции «интернет вещей», высокоскоростной обработки данных, создания промышленных роботов, технологий трехмерной печати, полной цифровой интеграции инженерно-конструкторских работ по всей цепочке создания стоимости. Для успешной цифровизации потребуется реализовать серию программ, направленных на обеспечение цифровой трансформации промышленности, разработать национальные стандарты и открыть центры компетенции по распространению информационно-коммуникационных, облачных, аддитивных и иных технологий, систем искусственного интеллекта. Особое внимание будет уделено формированию цифровых платформ взаимодействия промышленных организаций и созданию демонстрационных смарт-фабрик.
В условиях международной глобализации основные направления трансформации экономики связаны с международными цепочками добавленной стоимости. В этой связи существенно возрастает актуальность международной интеграции. В декабре 2016 г. в Санкт-Петербурге главы государств ЕАЭС приняли Заявление о цифровой повестке Евразийского экономического союза. Объединение усилий государств - членов ЕАЭС приобретает особую важность в период международной турбулентности и санкционного давления. Это позволяет существенно усилить конкурентные преимущества наших производителей. Следует отметить, что с 1996 г. реализовано свыше 50 научно-технических программ Союзного государства с участием крупнейших научно-исследовательских, научнопроизводственных и промышленных организаций Беларуси и России. В результате разработаны и внедряются уникальные образцы новой техники и технологий. Продолжается работа по формированию единого научно-технологического пространства. Цель - ускоренное использование достижений науки и технологий в инновационной деятельности. Речь идет и о совместной коммерциализации результатов инновационных проектов, и о привлечении межбюджетных источников финансирования, и о задействовании партнеров из третьих стран. Поэтому очень важна взаимная увязка нашей Программы социально-экономического развития на период 20212025 гг. с прогнозными и программными документами стран-партнеров (прежде всего, Союзного государства, ЕАЭС, СНГ). Потенциал экономики в рамках существующей модели только раскрывается. Новые условия будут формировать и новые возможности, которые станут реализовываться за счет новых технико-технологических и организационно-экономических решений.

Подводя итог, необходимо отметить, что сегодня цифровые возможности становятся не менее значимым фактором, чем доступность сырья, наличие финансовых ресурсов, а цифровая трансформация эко- 
номики как объективный процесс неизбежна и обусловлена НТП. Современный этап развития мировой экономики характеризуется наслоением перехлестывающихся волн шестого технологического уклада и четвертой промышленной революции, что предопределяет острую необходимость повышения инновационной восприимчивости национальной экономики, которая характеризуется скоростью и легкостью прохождения трансфера инноваций (технологий) и требует соответствующей адаптации экономической политики как в области целевых установок, так и в области инструментарных средств и механизмов их применения.

В качестве коммуникационной основы цифровой трансформации мировой хозяйственной системы выступают глобальные информационные сети, а организационной основой являются механизмы глобальной координации и синхронизации деятельности киберфизических систем как между собой, так и с социальными системами (включая государство). Их технологическая инфраструктура наравне с поддерживающей средой, формируемой экономической политикой государства, будет определять мировое экономическое пространство и темпы развития отдельных стран.

«Окна» возможностей как для отдельных субъектов хозяйствования, так и для промышленной политики государства в целом связаны прежде всего со спецификой цифровой трансформации ведущих предприятий в развитых странах. В условиях фрагментации технологических процессов, обусловленной специализацией промышленных производственных единиц, формируется мотивация для взаимного обмена технологиями и распространения инноваций вдоль международных цепочек добавленной стоимости. Налаживание производственно-хозяйственных связей отечественных предприятий с компаниями, входящими в число технологических лидеров, зависит от выработки новой модели адаптивной промышленной политики и внедрения процессно-ориентированного механизма согласования интересов субъектов промышленного развития страны.
Цифровая трансформация экономики как объективный процесс развития нашего общества неизбежна и обусловлена НТП. Очевидно, что преимущества будут у тех субъектов управления, которые смогут контролировать технологии (и технические средства), обеспечивающие координацию деятельности киберфизических систем. Основная задача социально ответственного государства в сложившихся условиях сохранить свое влияние в вопросах определения приоритетов экономической и социальной политики в соответствии с национальными интересами, обеспечить для этого контроль над используемыми информационными ресурсами, коммуникационными платформами, техническими и программными средствами передачи, хранения и обработки данных.

Человечество уже не раз сталкивалось с подобными вызовами и успешно справлялось с ними. Например, в свое время существенные преобразования в нашей жизни произошли благодаря появлению и развитию автотранспорта, широкое распространение которого вместе с новыми возможностями принесло новые опасности. Пришлось изобретать правила дорожного движения и организовывать ДПС, ограничивать скорость передвижения и штрафовать за нарушения. Распространение цифровых технологий и использование искусственного интеллекта несет много опасностей, но и много новых возможностей. Человечество сможет найти способ регулировать и контролировать эти процессы, создавать защитные механизмы, ограничивать некоторые возможности. Каждому придется научиться разумно пользоваться новыми технологиями, а обществу выработать коллективный информационный иммунитет.

\section{СПИСОК ЛИТЕРАТУРЫ (REFERENCES)}

Байнев В.Ф., Бинь Ч. 2017. «Четвертая промышленная революция» как технико-технологический и политико-экономический феномен. Hoвая экономика. № 1. C. 4-10. [Bainev V.F., Bin' Ch. 2017. Novaya ekonomika. No 1. PP. 4-10. (In Russ.)]

Богдан Н.И. 2018. Инновации и человеческие ресурсы для развития цифровой экономики. 
Белорусский экономический журнал. № 3. С. 110123. [Bohdan N. 2018. Innovations and human resources for digital economy development. Belorusskiy ekonomicheskiy zhurnal. No 3. PP. 110123. (In Russ.)]

Глазьев С.Ю. 2017. Великая цифровая экономика. Социальная политика и сощиальное партнерство. № 11. С. 5-26. [Glaz'ev S.Yu. 2017. Great digital economy. Sotsial'naya politika $i$ sotsial'noe partnerstvo. No 11. PP. 5-26. (In Russ.)]

Гурский В.Л. 2017. Промышленная политика как фактор повышения инновационной восприимчивости в условиях цифровой трансформации экономики. Стратегия развития экономики Беларуси: вызовы, инструменты реализации и перспективы. Ч. 2. Минск: Институт системных исследований в АПК НАН Беларуси. С. 219-224. [Gurskij V.L. 2017. Industrial policy as a factor in increasing innovation susceptibility in the context of the digital transformation of the economy. Strategiya razvitiya ekonomiki Belarusi: vyzooy, instrumenty realizatsii $i$ perspektioy. Part 2. PP. 219-224. (In Russ.)]

Кастельс М. 2000. Информационная эпоха: экономика, общество и культура. Москва: ГУ ВШЭ. 608 c. [Castells M. 2000. The Information Age: Economy, Society and Culture. Moscow: GU VShE. 608 p. (In Russ.)]

Ковалев М.М., Головенчик Г.Г. 2018. Цифровая экономика - шанс для Беларуси. Минск: Издательский центр БГУ. 328 с. [Kovalev M.M., Golovenchik G.G. 2018. Digital economy is a chance for Belarus. Minsk: Izdatel'skiy tsentr BGU. 328 p. (In Russ.)]

Козырев А.Н. 2018. Цифровая экономика и цифровизация в исторической перспективе. Цифровая экономика. № 1. C. 5-19. [Kozyrev A.N. 2018. Digital economy and digitalization in historical retrospect. Tsifrovaya ekonomika. No 1. PP. 5-19. (In Russ.)]

Лемещенко П.С. 2019. Институциональные аспекты этапа цифровизации политэкономического и социального развития. Теоретическая экономика. № 12. C. 34-37. [Lemeshenko P.S. 2019. Institutional aspects of the digitalization phase political economic and social development. Teoreticheskaya ekonomika. No 12. PP. 34-37. (In Russ.)]

Мелешко Ю.В. 2018. Перспективы развития рынка интернета вещей в Республике Беларусь. Экономическая наука сегодня. № 7. С. 4962. [Meleshko Yu.V. 2018. Prospects for the development of the internet of things market in the Republic of Belarus. Ekonomicheskaya nauka segodnya. No 7. PP. 49-62. (In Russ.)]
Никитина А.С., Борисенко И.И. 2020. Цифровая трансформащия государственного управления. Екатеринбург: Уральский государственный педагогический университет. 140 c. [Nikitina A.S., Borisenko I.I. 2020. Digital transformation of public administration. Ekaterinburg: Ural'skiy gosudarstvennyy pedagogicheskiy universitet. 140 p. (In Russ.)]

Паньшин Б.Н. 2016. Цифровая экономика: особенности и тенденции развития. Наука и инновации. № 3. С. 17-20. [Panshin B. 2016. Digital economy: features and development trend. Nauka $i$ innovatsii. No 3. PP. 17-20. (In Russ.)]

Сергиевич T.B. 2019. Технологизация в современной экономике: на примере производства товаров интенсивного обновления. Экономическая наука сегодня. Вып. 9. С. 192-199. [Serhiyevich T.V. 2019. Technologization in modern economy: On the example of production of goods of intensive renewal. Ekonomicheskaya nauka segodnya. Iss. 9. PP. 192-199. (In Russ.)]

Солодовников С.Ю. 2019. Сетевые механизмы инновационного развития как инструмент перехода к новому качеству экономического роста в условиях экономики рисков. Право. Экономика. Психология. № 4. С. 30-36. [Solodovnikov S.Y. 2019. Network mechanisms of innovative development as a tool for the transition to a new quality of economic growth in the context of the risk economy. Pravo. Ekonomika. Psihologiya. No 4. PP. 30-36. (In Russ.)]

Филиппова И.А., Незванов Д.Д. 2018. Развитие цифровой экономики в России. Вестник Ульяновского государственного технического университета. № 3. C. 54-56. [Filippova I.A., Nezvanov D.D. 2018. Development of digital economy in Russia. Vestnik Ul'yanovskogo gosudarstvennogo tekhnicheskogo universiteta. No 3. PP. 54-56. (In Russ.)]

Шваб К. 2016. Четвертая промышленная револющия. Москва: Эксмо. 138 с. [Schwab K. 2016. The fourth industrial revolution. Moscow: Eksmo. 138 р.]

Юдина Т.Н. 2016. Осмысление цифровой экономики. Теоретическая экономика. № 3. С. 1216. [Yudina T.N. 2016. Understanding the digital economy. Teoreticheskaya ekonomika. No 3. PP. 1216. (In Russ.)]

Johansson B., Karlsson Ch., Stough R. 2006. The Emerging Digital Economy: Entrepreneurship, Clusters, and Policy. Berlin: Springer Science \& Business Media. 352 p.

Mesenbourg T. 2001. Measuring the Digital Economy. Suitland, MD: US Bureau of the Census. 
In citation: Belorusskiy Ekonomicheskiy zhurnal. 2021. No 3. PP. 4-14.

Belarusian Economic Journal. 2021. No 3. PP. 4-14.

\title{
THE PHENOMENON OF DIGITAL TRANSFORMATION OF THE ECONOMY IN THE DEVELOPMENT OF SOCIETY
}

\author{
Vasili Hursky ${ }^{1}$ \\ Author affiliation: ${ }^{1}$ Institute of Economics of the National Academy of Sciences of Belarus (Minsk, \\ Belarus). \\ Corresponding author: Vasili Hursky (vhurski@yandex.by).
}

ABSTRACT. The article studies phenomenological foundations of the economy digital transformation under changes in socio-economic relations caused by the evolution of means of production as a result of scientific and technological progress. It also analyzes the main advantages and threats associated with the digital transformation of the society. State control over information resources, communication platforms, hardware and software for transmission, processing and storage of data is considered as a prerequisite for reducing its risks.

KEYWORDS: digital economy, digital transformation, cyber-physical complexes, virtual reality.

JEL-code: O33.

DOI: $10.46782 / 1818-4510-2021-3-4-14$

Received 30.07.2021 